\title{
A constituent comparison model of a picture-first verification task
}

\author{
MURRAY SINGER \\ University of Manitoba, Winnipeg, Canada R3T 2N2
}

\begin{abstract}
In a recent critique of Carpenter and Just's (1975) verification model, Tanenhaus, Carroll, and Bever (1976) pointed out that the estimates of the comparison parameter of the model varied considerably among tasks. In particular, estimates of this parameter were higher for picture-first than for sentence-first sentence-picture verification tasks. The picture-first estimates, however, were based upon an analysis of only a subset of the trials: namely, those in which the preposition "above" was embedded in the sentence. When a more comprehensive model is applied to the data of picture-first experiments, the estimates of the comparison operation are comparable to those based on sentence-first tasks.
\end{abstract}

Carpenter and Just (1975) have described a model of verification which provides predictions concerning response latencies in a wide variety of tasks. The authors posit the existence of a mental operation which permits the comparison of corresponding pairs of constituents (hence, constituent comparison) in the internal representations of the elements to be verified (e.g., a sentence with a picture; two sentences; a sentence with information stored in memory). Latency predictions are thus based upon this single comparison parameter, whereas other investigators describe sets of two to four parameters to achieve such predictions (Chase \& Clark, 1972; Clark \& Chase, 1972; Trabasso, Rollins, \& Shaughnessy, 1971). A second distinctive property of the model is that the comparison process is assumed to restart with the first pair of constituents whenever a pair of constituents mismatch. Carpenter and Just (1975) suggest that this reinitialization may result from short-term memory limitations.

The success of this approach will depend, to a great extent, upon the ability to obtain consistent estimates of the magnitude of the comparison parameter across tasks. In their examination of numerous sentence-picture verification tasks, however, Carpenter and Just (1975, Table 4) obtain estimates that range from $97 \mathrm{msec}$ to 390 msec. While the authors do not express much dissatisfaction with this range, Tanenhaus, Carroll, and Bever (1976) have recently pointed out that the picture-first condition tends to provide larger estimates of the comparison parameter than does the sentencefirst condition. The comparison parameter thus lacks the consistency of other elementary mental operations, such as the scan of memory (Cavanagh, 1972; Sternberg, 1969).

This research was supported by a grant from the National Research Council of Canada, Number 311-1665-04. Reprint requests should be addressed to Murray Singer, Department of Psychology, University of Manitoba, Winnipeg, Manitoba, Canada R3T 2N2.
For any given task, the Carpenter and Just model consists of the specification of the number of comparison operations required for each problem type, in relation to the number $(\mathrm{k})$ necessary for the simplest problem. For picture-first verification of sentences and pictures, the authors indicate that $\mathrm{k}, \mathrm{k}+1, \mathrm{k}+2$, and $k+3$ operations are executed for true affirmative (TA), false affirmative (FA), false negative (FN), and true negative (TN) exemplars, respectively. An examination of Table 4 in Carpenter and Just (1975) reveals that, for picture-first experiments, only problems falling in the "above" condition were included in the analysis. Since Carpenter and Just typically separate the analysis of "above" and "below" problems, the procedure seems to imply that the $(k, k+1, k+2$, $\mathrm{k}+3$ ) model would apply equivalently to "below" problems. An inspection of the picture-first data of Clark and Chase (1972, Table 5) reveals that this is not the case. Clark and Chase's observed latencies were $2,139,2,077,2,678$, and 2,499 for TA, FA, FN, and $\mathrm{TN}$, respectively. This order is inconsistent with the model, which predicts TA $<$ FA, and FN $<$ TN.

Clark and Chase (1972) argue that recoding of the sentence representation occurs in the picture-first task when the subjects of the embedded strings of the sentence and picture mismatch. Carpenter and Just's picture-first model fails for "below" problems because it does not take this into account. What is needed is a more comprehensive model for the picture-first task. Such a model is readily constructed, making reference to the principles described by Carpenter and Just. In a typical problem, the subject looks at a picture such as "*," and then at a sentence such as "The star is not below the plus." The picture is encoded as "[aff (plus, top)]." It is unnecessary to include reference to the star since, with only two possible shapes, its inclusion would be redundant for this task (Carpenter \& Just, 1976). The encoding of the sentence is "[neg (star, bottom)]," where the inner or embedded string refers explicitly to the subject and 
the preposition of the sentence. In the course of comparison, inner strings such as "star, bottom" will be recoded to the equivalent "plus, top" if the subjects of the sentence and picture encodings mismatch; as is the case for the present example. From this point, comparisons will proceed as described by Carpenter and Just.

One question arises in the application of these principles: namely, whether the recoding of the inner string involves one comparison or two. While Carpenter and Just (Table 6) treated the recoding of the inner string as a single operation in a recoding task (subjects were explicitly instructed to recode negatives to affirmatives), this recoding involved altering only one of the inner string elements (e.g., "star, top" becomes "plus, top"). In the picture-first task, both elements of the inner string are changed. An answer to this question can be approached on empirical grounds, with reference to the picture-first data of Clark and Chase, in which it is seen that recoding stands in the ratio of $2.3: 1$ in comparison with falsification time. The same ratio based on the picture-first data of Singer and Chase (Note 1) is 1.9:1. Since the falsification parameter of Clark and Chase (1972) corresponds to the execution of one comparison operation, it is concluded that, for the picture-first task, recoding consists of two comparisons.

The application of these principles to the picturefirst task is shown in Table 1 . The resulting model specifies $k, k+2, k+3, k+1, k+5, k+3, k+2$, and $\mathrm{k}+4$ comparison operations for TA-above, TA-below, FA-above, FA-below, TN-above, TN-below, FN-above, and FN-below problems, respectively. To test the model, it is necessary, however, to consider the fact that there

Table 1

Representations and Predictions for Eight Problem Types

\begin{tabular}{|c|c|c|c|c|}
\hline $\begin{array}{l}\text { Stimulus and } \\
\text { Representation }\end{array}$ & Above & Below & Above & Below \\
\hline & \multicolumn{2}{|c|}{ True Affirmative } & \multicolumn{2}{|c|}{ False Affirmative } \\
\hline Picture & * & $\begin{array}{l}* \\
+\end{array}$ & $\stackrel{*}{+}$ & * \\
\hline $\begin{array}{l}\text { Picture } \\
\text { Representation }\end{array}$ & [aff (star, top)] & [aff (star, top)] & [aff (star, top)] & {$[$ aff (star, top)] } \\
\hline Sentence & $\begin{array}{l}\text { The star is above } \\
\text { the plus. }\end{array}$ & $\begin{array}{l}\text { The plus is below } \\
\text { the star. }\end{array}$ & $\begin{array}{l}\text { The plus is above } \\
\text { the star. }\end{array}$ & $\begin{array}{c}\text { The star is below } \\
\text { the plus. }\end{array}$ \\
\hline $\begin{array}{l}\text { Sentence } \\
\text { Representation }\end{array}$ & [aff (star, top)] & [aff (plus, bottom)] & [aff (plus, top)] & [aff (star, bottom)] \\
\hline $\begin{array}{l}\text { Recoding } \\
\text { Operations }\end{array}$ & none & + & + & none \\
\hline $\begin{array}{l}\text { Recoded } \\
\text { Sentence }\end{array}$ & no change & [aff (star, top)] & [aff (star, bottom)] & no change \\
\hline Comparisons & $+\quad+$ & $+\quad+$ & $+\quad+$ & + \\
\hline Response & True & True & False & False \\
\hline \multirow[t]{2}{*}{$\begin{array}{l}\text { Number of } \\
\text { Comparisons }\end{array}$} & $\mathbf{k}$ & $k+2$ & $k+3$ & $k+1$ \\
\hline & \multicolumn{2}{|c|}{ True Negative } & \multicolumn{2}{|c|}{ False Negative } \\
\hline Picture & + & $\stackrel{*}{+}$ & $\stackrel{*}{+}$ & $\stackrel{*}{+}$ \\
\hline $\begin{array}{l}\text { Picture } \\
\text { Representation }\end{array}$ & [aff (star, top)] & {$[$ aff (star, top)] } & [aff (star, top)] & {$[$ aff (star, top) $]$} \\
\hline Sentence & $\begin{array}{c}\text { The plus is not above } \\
\text { the star. }\end{array}$ & $\begin{array}{c}\text { The star is not below } \\
\text { the plus. }\end{array}$ & $\begin{array}{c}\text { The star is not above } \\
\text { the plus. }\end{array}$ & $\begin{array}{c}\text { The plus is not below } \\
\text { the star. }\end{array}$ \\
\hline $\begin{array}{l}\text { Sentence } \\
\text { Representation }\end{array}$ & [neg (plus, top)] & [neg (star, bottom)] & [neg (star, top)] & [neg (plus, bottom)] \\
\hline $\begin{array}{l}\text { Recoding } \\
\text { Operations }\end{array}$ & $+\quad+$ & none & none & 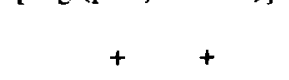 \\
\hline $\begin{array}{l}\text { Recoded } \\
\text { Sentence }\end{array}$ & [neg (star, bottom)] & no change & no change & [neg (star, top)] \\
\hline Comparisons & $\begin{array}{ll}- & + \\
+ & +\end{array}$ & $\begin{array}{l}- \\
+\end{array}$ & $+\quad+$ & $+\quad+$ \\
\hline Response & True & True & False & False \\
\hline $\begin{array}{l}\text { Number of } \\
\text { Comparisons }\end{array}$ & $k+5$ & $k+3$ & $k+2$ & $k+4$ \\
\hline
\end{tabular}


Table 2

Observed and Predicted Latencies and Parameter Estimates of the Regression Analysis

\begin{tabular}{|c|c|c|c|c|c|c|c|c|c|c|c|c|c|}
\hline & \multicolumn{8}{|c|}{ Condition } & & & & & \multirow{3}{*}{$\begin{array}{c}\text { Vari- } \\
\text { ance Ac } \\
\text { counted } \\
\text { For }\end{array}$} \\
\hline & \multicolumn{2}{|c|}{ True } & \multicolumn{2}{|c|}{ False } & \multicolumn{2}{|c|}{ True } & \multicolumn{2}{|c|}{ False } & \multicolumn{4}{|c|}{ Parameters } & \\
\hline & Above & Below & Above & Below & Above & Below & Above & Below & compar & $\mathrm{b}$ & $\mathrm{c}$ & base & \\
\hline \multicolumn{14}{|c|}{ Data of Clark and Chase, Experiment 2} \\
\hline $\begin{array}{l}\text { Observed } \\
\text { Predicted }\end{array}$ & $\begin{array}{l}1783 \\
1814\end{array}$ & $\begin{array}{l}2139 \\
2148\end{array}$ & $\begin{array}{l}2130 \\
2123\end{array}$ & $\begin{array}{l}2077 \\
2045\end{array}$ & $\begin{array}{l}2614 \\
2627\end{array}$ & $\begin{array}{l}2499 \\
2549\end{array}$ & $\begin{array}{l}2354 \\
2318\end{array}$ & $\begin{array}{l}2678 \\
2652\end{array}$ & $103(13)$ & 298 ( 39) & $128(29)$ & 1814 & $99.00 \%$ \\
\hline $\begin{array}{l}\text { Observed } \\
\text { Predicted }\end{array}$ & $\begin{array}{l}1909 \\
1942\end{array}$ & $\begin{array}{l}2250 \\
2360\end{array}$ & $\begin{array}{l}2279 \\
2248\end{array}$ & $\begin{array}{l}2374 \\
2258\end{array}$ & $\begin{array}{l}3089 \\
3114\end{array}$ & $\begin{array}{l}3106 \\
3124\end{array}$ & $\begin{array}{l}2840 \\
2808\end{array}$ & $\begin{array}{l}3333 \\
3226\end{array}$ & $102(36)$ & $662(109)$ & $214(81)$ & 1942 & $97.00 \%$ \\
\hline
\end{tabular}

Note-Standard errors are shown in parentheses.

exist negation and above-below effects in the encoding of sentences, independent of the comparison activities that are the main focus of the model (Singer, Chase, Young, \& Clark, Note 2). That is, it takes longer to encode a negative than an affirmative sentence, and longer to encode the preposition "below" than the preposition "above." For this reason, a regression model was constructed which includes four parameters: the comparison operation (compar); encoding negation time (b); encoding above-below time (a); and a base parameter $(t)$. While the addition of the encoding parameters may seem to be contrary to the "parsimony" that Carpenter and Just ascribe to their model, it should be kept in mind, for example, that Carpenter and Just examined "above" and "below" problems separately. This, of course, eliminated the need for an above-below parameter.

The present model was first applied to the picturefirst data of Clark and Chase (1972, Table 5), and the outcome is shown in Table 2. The three parameters were stepped into the regression equation in the order compar, b, and a, and the analysis provided estimates of 103, 298, and $128 \mathrm{msec}$, respectively. The standard error for compar was $13 \mathrm{msec}$. Each of the three parameters accounted for a significant portion of the remaining variance. Together, the three parameters accounted for $99 \%$ of the variance among the eight means.

For a second test, the model was applied to the mean response latencies for the picture-first experiment conducted by Singer and Chase (Note 1). In this case, estimates of 102,662 , and 214 were obtained for compar, $b$, and a, respectively (Table 2). The standard error for compar was $36 \mathrm{msec}$. Each parameter accounted for a significant portion of the remaining vairance [although $\mathbf{F}(1,4)=7.00, p<.06$ for $a$ ], and together they accounted for $97 \%$ of the variance among the eight means.

\section{DISCUSSION}

The present picture-first model that is based on the principles specified by Carpenter and Just makes accurate predictions concerning response latencies of the eight problem types. What can be learned from the magnitude of the parameters obtained from the regression analysis? First, the above-below parameters fell well within the range obtained in other experiments. They presumably reflect subjects' difficulty in encoding "below" as compared with encoding "above."

Second, the encoding negation time parameter based on the analysis of Clark and Chase's (1972) data $(298 \mathrm{msec})$ is in reasonable agreement with that obtained by Trabasso et al. (1971, Table 5). These investigators measured encoding negation time directly, by separating the encoding and comparison phases in a verification task. The much higher estimate of $b$ derived from the data of Singer and Chase (Note 1) is assumed to be at least partly due to the fact that these authors did not discard the first block of practice in their computation of mean response latency, as had Clark and Chase (1972). This was because Singer and Chase were explicitly examining practice effects. They found that the Clark and Chase negation time parameter bd (which combines the encoding and verification stage negation parameters) dropped from about $1,100 \mathrm{msec}$ for Block 1 to about $600 \mathrm{msec}$ for Block 10. When they applied constituent comparison analysis to the same data, however, compar was found to diminish only from $139 \mathrm{msec}$ (Block 1) to $95 \mathrm{msec}$ (Block 10). The inclusion of the Block 1 data, therefore, is likely to distort the estimate of $b$ much more than that of compar.

Third, and most important, the magnitude of the comparison operation was 103 and $102 \mathrm{msec}$ for the two sets of data examined. The fact that these estimates are almost identical is less relevant than their comparability to the values reported by Carpenter and Just (1975) for sentence-first studies. It would thus appear that the estimates of 272 to $390 \mathrm{msec}$ that Carpenter and Just obtained for the comparison operation of picture-first tasks may have been a function of the application of the model to the "above" means only.

Certainly, it is the case that, if an incomplete or incorrect constituent comparison model is applied to a set of data, a discrepant estimate of the comparison 
operation will be obtained. To illustrate this, the present model was applied to the data of Clark and Chase's (1972) Experiment 3. In this experiment, subjects were instructed to encode the picture either by examining (1) the entire figure, (2) the top only, or (3) the bottom only. While the "top" condition approximates the usual strategy for picture encoding in this task, the "bottom" condition does not. Therefore, the present model should make accurate predictions concerning the latencies for the "top" but not the "bottom" condition. The model, in fact, accounts for $99.8 \%$ of the variance among the "top" means, and the comparison operation receives a value of $122 \mathrm{msec}$. When it was applied to the means of the "bottom" condition, however, the model accounted for only $84.4 \%$ of the variance. The estimate provided for the comparison operation was $-40 \mathrm{msec}$, a nonsensical value.

By way of contrast, a variant of the present model was constructed. This version specified the encoded form of the picture "*" as "[aff (plus, bottom)]," rather than "[aff (star, top)]," for the "bottom" condition. The application of this model to the data of Clark and Chase's "bottom" condition accounted for $96.5 \%$ of the variance among the eight means. The comparison operation received an estimated value of $110 \mathrm{msec}$.

Unexplained here is that the recoding parameter (Clark \& Chase, 1972, Experiment 3, "bottom") stands in a ratio about $1: 1$ with falsification, rather than $2: 1$. It is possible to speculate that the response latency means for this condition are based upon a combination of subject strategies, rather than upon a uniform one. Carpenter and Just $(1976$, p. 320) describe some of the determinants of subjects' strategy selection. Under certain conditions, different subjects may employ different strategies; or a majority of subjects may shift from one strategy to another. In these circumstances, the attempt to fit to the data a model representing a uniform strategy will yield inappropriate parameter values. Carpenter and Just (1975, p. 66), in fact, discuss one case in which the most appropriate model is based upon a mixture of strategies, and which specifies $k+2.5$ comparison operations for true and false negative problems. For the bottom condition of Clark and Chase's Experiment 3, a strategy mixture may be the basis of the $1: 1$ recoding to falsification ratio. It may also account for the fact that the "bottom" condition model of the present analysis accounted for only $96.5 \%$ of the variance among means, as compared with $99.8 \%$ for the "top" condition.

Carpenter and Just $(1975,1976)$ emphasize the role of their verification model in identifying the processing invariants among tasks. Accordingly, the viability of their formulation should depend at least in part upon an ability to obtain, across tasks, consistent estimates of the comparison parameter. It is elsewhere argued that, until we can specify "standard conditions" in psychological experimentation, it might be unreasonable to demand consistent parameter estimates of such models. It seems reasonable, on the other hand, to pursue such inconsistencies that do appear, and to identify their source, whether it be differences in the practice level of subjects or the incompleteness of the model. If consistent estimates can be obtained for the comparison time parameter, this will support the credibility of the model and the psychological reality of the operation. If consistent estimates are not obtained, it will be possible to use this information to expand or to revise the model.

\section{REFERENCE NOTES}

1. Singer, M., \& Chase, W. G. Practice effects in a verification task. In preparation.

2. Singer, M., Chase, W. G., Young, R. M., \& Clark, H. H. Practice effects in the comparison of sentences and pictures. Paper presented at the Annual Meeting of the Midwestern Psychological Association, Detroit, May 1971.

\section{REFERENCES}

Carpenter, P. A., \& Just, M. A. Sentence comprehension: A psycholinguistic model of verification. Psychological Review, 1975, 82, 45-73.

Carpenter, P. A., \& Just, M. A. Models of sentence verification and linguistic comprehension. Psychological Review, 1976, 83, 318-322.

CavanaGh, J. P. The relation between the immediate memory span and memory search rate. Psychological Review, 1972, 79, $525-530$

Chase, W. G., \& Clark, H. H. Mental operations in the comparison of sentences and pictures. In L. Gregg (Ed.), Cognition in learning and memory. New York: Wiley, 1972.

Clark, H. H., \& Chase, W. G. On the process of comparing sentences against pictures. Cognitive Psychology, 1972, 3, 472-517.

STERnberg, S. Memory scanning: Mental processes revealed by reaction-time experiments. American Scientist, 1969, 57, 421-457.

Tanenhaus, M. K., Carroll, J. M., \& Bever, T. G. Sentence-picture verification models as theories of sentence comprehension: $A$ critique of Carpenter and Just. Psychological Review, 1976, 83, 310-317.

Trabasso, T., Rollins, H., \& Shaughnessy, E. Storage and verification stages in processing concepts. Cognitive Psychology, 1971, 2, 239-289.

(Received for publication December 13, 1976; accepted January 12, 1977.) 